Cuadernos de Filología Clásica. Estudios Latinos

ISSN: 1131-9062

http://dx.doi.org/10.5209/cfcl.73012

\title{
«A dream within a dream»: liminalidad y creación poética en Lavinia de Ursula Le Guin y El silbido del arquero de Irene Vallejo
}

\author{
Daniel Nisa Cáceres ${ }^{1}$; Rosario Moreno Soldevila ${ }^{2}$
}

Recibido: 6 de septiembre de 2020 / Aceptado: 29 de noviembre de 2020

Resumen. En este trabajo se estudian de manera comparada dos novelas contemporáneas que recrean la Eneida de Virgilio: Lavinia, de Ursula K. Le Guin, y El silbido del arquero, de Irene Vallejo. En ellas Lavinia y Ana, personajes femeninos secundarios en el poema épico, se hallan interconectadas con el personaje de Virgilio, la primera mediante el diálogo directo y la conciencia de su propia naturaleza fictiva, y a través de la caracterización y la intratextualidad la segunda. Ambas protagonistas comparten su carácter liminal: viven a caballo entre distintos mundos, la infancia y la edad adulta, los poderosos y los humildes, el palacio y la naturaleza, lo divino y lo humano, la vida y la muerte. Su historia es y no es la que cuenta la Eneida. Su identidad metafictiva y liminal las convierte en vehículos para la reflexión sobre la creación poética virgiliana, tema central de estas novelas.

Palabras clave: Ursula K. Le Guin; Irene Vallejo; Virgilio; Lavinia; El silbido del arquero; la Eneida.

\section{[en] «A dream within a dream»: Liminality and poetic creation in Ursula Le Guin's Lavinia and Irene Vallejo's El silbido del arquero}

\begin{abstract}
This paper is a comparative study of two contemporary novels which rewrite Virgil's Aeneid: Ursula K. Le Guin's Lavinia and Irene Vallejo's El silbido del arquero. Two secondary female characters in the epic poem, Lavinia and Anna, are closely related to Virgil's presence as a character through Lavinia's direct dialogues with him and her metafictional self-awareness, and, in the case of Ana, in terms of characterisation and intratextuality. Both protagonists are liminal figures: they live on the borderline between different worlds, childhood and adulthood, the powerful and the lowly, palace life and nature, the divine and the human, life and death. Their stories are simultaneously told and untold in the Aeneid. Their metafictional and liminal identity turns them into vehicles for a meditation on Virgil's poetic creation, a key element to these narratives.
\end{abstract}

Keywords: Ursula K. Le Guin; Irene Vallejo; Virgil; Lavinia; El silbido del arquero; the Aeneid.

Sumario: 1. Introducción. 2. Lavinia de Ursula Le Guin. 2.1. Estructura narrativa de la novela. 2.2. Conversando con Virgilio: figuras y procesos liminales. 2.3. Lavinia desde su atalaya. 2.4. "That knowledge changed nothing»: a vueltas con el destino. 2.5. "An owl flitting in the dark oaks of Albunea»: Lavinia como lechuza. 2.6. «Tell me I can finish my work!»: liminalidad y (re-)creación. 3. El silbido del arquero de Irene Vallejo. 3.1. Ana en El silbido del arquero. 3.2. Ana, entre el palacio y la calle. 3.3. Ana, entre los niños y los adultos. 3.4. Ana y las palabras. 3.5. Ana, entre los dioses y los

Universidad Pablo de Olavide, de Sevilla.

Correo electrónico: dniscac@upo.es

2 Universidad Pablo de Olavide, de Sevilla.

Correo electrónico: rmorsol@upo.es 
mortales. 3.6. Mar adentro. 3.7. Ana y Virgilio. 4. Conclusión: lo liminal como reflexión metapoética. 5. Bibliografía.

Cómo citar: Nisa Cáceres, D.; Moreno Soldevila, R., «“A dream within a dream”: liminalidad y creación poética en Lavinia de Ursula Le Guin y El silbido del arquero de Irene Vallejo», Cuad. Filol. Clás. Estud. Lat. 40.2 (2020), 345-366.

\section{Introducción}

Durante más de veinte siglos la Eneida ha estimulado, tal vez como ninguna otra obra clásica, la imaginación de occidente, en un diálogo permanente entre lectores y creadores con Virgilio ${ }^{3}$. En las últimas décadas el gran poema épico ha inspirado una creciente constelación de novelas y relatos escritos por mujeres ${ }^{4}$, que invitan a reflexionar sobre tribulaciones actuales, indagando, por añadidura, en el propio hecho de la creación literaria desde el centro y desde los márgenes.

Dos de estas novelas, pese a sus diferencias, se prestan a leerse como un díptico: Lavinia, de la autora de fantasía y ciencia ficción estadounidense Ursula K. Le Guin, y El silbido del arquero, de la filóloga clásica española Irene Vallejo, obras nacidas del amor profundo al poema virgiliano 5 . Ambas exploran otras 'Eneidas' posibles que iluminan la original con otras perspectivas y voces, incluida la del poeta ficcionalizado. Las dos novelas comparten mucho más que la inspiración virgiliana: como narrativas postmodernas, aportan una revisión del poema épico desde los márgenes, incorporando la voz femenina de personajes secundarios; comparten el carácter metaliterario, ya que Virgilio aparece como personaje de la trama e interactúa con sus creaciones mientras concibe o repiensa el poema en dos momentos distintos del proceso creativo, pero igualmente traumáticos; los límites entre realidad y ficción se difuminan, como lo hacen las barreras espacio-temporales; ambos relatos desarrollan hilos argumentales complementarios, exploran caminos alternativos, pero en la dicotomía entre agencia y determinismo consagran la Eneida como el poema que tenía que haber sido. La trama virgiliana se despoja en las dos novelas de la intervención del aparato divino, aunque la religión ocupa un papel central en ambas obras y el dios Eros es uno de los personajes-narradores en El silbido del arquero, como se verá. Junto con algunos paralelismos en la trama, que se señalarán oportunamente, llama la atención la sintonía en la caracterización de los dos personajes femeninos objetos de este estudio, Lavinia y Ana, cuyo carácter liminal las conecta con el poeta y las convierte en vectores de la exploración metafictiva. La voz de Lavinia, muda

La bibliografía sobre la tradición literaria de la Eneida es ingente. Pueden consultarse, sin ánimo de exhaustividad, Harrison 1990; Martindale 1997; Farrell y Putnam 2010; Ziolkowski y Putnam 2008; Hardie 2014; Álvarez et al. 2019.

Fenómeno estudiado por Cox 2011.

Para Lavinia, seguimos la primera edición británica de 2009; para El silbido del arquero, la edición de 2015; para la Eneida, Rivero et al. (2009-2011). Lavinia ha sido estudiada desde diferentes enfoques: Lindow 2009; Miller 2010; Rea 2010; Cox 2011; Byrne 2012; Brown 2012; Behr 2014; Provini 2014; Cristóbal 2015; Cantó Llorca 2016; Haydock 2018; Small 2018; Teodoro Peris 2019; Bugada 2019; Walde 2019. Sobre El silbido del arquero, no hay aún bibliografía crítica, excepto la atinada reseña de Martino 2017. 
en la Eneida, y la de Ana, redimensionada, pueden interpretarse, por su liminalidad, como vehículos para la reflexión sobre la angustia de la creación literaria.

Como estado intermedio de los ritos de paso, donde el individuo ya se ha despojado de su identidad previa pero aún no ha franqueado el umbral de la transformación y se encuentra en una suerte de estatismo transicional, lo liminal abarca, en palabras del antropólogo Victor Turner, situaciones y objetos que están «"betwixt and between'» y que atañen a sujetos individuales, grupos o grandes civilizaciones, combinándose a su vez tanto con una dimensión temporal como espacial en diversos grados según los modelos tripartitos de Arnold van Gennep (Thomassen 2014, 89-90). En el caso de Lavinia y Ana, su liminalidad compartida adquiere un sentido más amplio, no necesaria o exclusivamente transicional, que se manifiesta como indeterminación, medianía o estado fronterizo espaciotemporal, sociocultural y literario $^{6}$ inherente a la metaficción historiográfica. En ella se coloca en primer plano el proceso de negociación de las contradicciones postmodernas -incluyendo cuestiones de género y cambio social, relaciones de poder y autoridad, o procesos de creación artística y cultural-, y no «any satisfactorily completed and closed product that results from their resolution» (Hutcheon 1988, xi); dicha cualidad inconclusa, abierta y liminal del postmodernismo también invita al escrutinio crítico de «the paradoxes of fictive/historical representation, the particular/the general, and the present/the past» (ibid. 106) que exhiben las complejas interrelaciones entre el texto virgiliano y su bimilenaria tradición de recreaciones, donde se hallan Lavinia y El silbido del arquero por derecho propio.

\section{Lavinia de Ursula Le Guin}

Le Guin (1929-2018) abre su última novela, Lavinia (2008), con una prolepsis narrativa: su homónima protagonista, cumpliendo su tarea de ir a recoger fango salado a la desembocadura del Tíber, tras despertar y beber agua del río sagrado e invocarlo, es la primera en otear los barcos troyanos y al mismísimo Eneas: «His face is stern yet unguarded; he is looking ahead into the darkness, praying. I know who he is» (2). Desde una posición privilegiada que le permite, como en tantas ocasiones en la novela, ver sin ser vista y oír sin ser oída, Lavinia posee la perspicacia necesaria para ahondar en su fuero interno y reconocer al héroe sin, paradójicamente, haberlo visto antes, en un alarde de anticipación a la secuencia cronológica de los acontecimientos. El hecho volverá a relatarse más adelante, en el lugar temporal que le corresponde: orantes, en una actitud receptiva para trascender su propia mortalidad y entrar en comunión con las potencias divinas, ambos se encuentran en una encrucijada espacial, la unión del agua dulce del río con la salada del mar, significante que, en virtud de su naturaleza liminal, de umbral de paso entre dos mundos, anticipa los cambios profundos y los trances que el destino les tiene reservados. La encrucijada es también temporal: «the twilight of morning» (100), el paso de la noche al día, del sueño a la vigilia.

Desde las primeras páginas, Lavinia es plenamente consciente de su condición de personaje de ficción y narradora intradiegética, pero advierte al lector de que no es la

Para los complejos desarrollos teóricos del concepto en los estudios literarios, cf. e.g. Viljoen et al. 2007, 1-26;

Kay et al. 2007, 7-16; Klapcsik 2012. 
Lavinia mencionada de pasada en la Eneida virgiliana, «sketched as if with a brass pin on a wax tablet» (5):

I know who I was, I can tell you who I may have been, but I am now, only in this line of words I write. I'm not sure of the nature of my existence, and wonder to find myself writing (3).

$\mathrm{Su}$ ser es inestable, incierto, contradictorio, sujeto a una condicionalidad ontológica entre dos mundos, la palabra hablada y la palabra escrita; entre dos cosmos, el fictivo y el metafictivo. Ha cambiado y ahora, con asombro, solo existe en sus propias palabras. Estas la apremian a encontrar respuestas, a seguir transformándose.

\subsection{Estructura narrativa de la novela}

A medio camino entre la autobiografía y la Bildungsroman, Lavinia narra en primera persona la historia de su protagonista desde la niñez hasta la muerte, trascendiendo los parámetros temporales que delimitan su presencia en la Eneida, en los libros VII-XII ${ }^{7}$. Lavinia cuenta su infancia y juventud, cuando se suceden las visitas del espectro de Virgilio en Albúnea, lugar sagrado y enclave liminal por excelencia. Sus sucesivas conversaciones con el poeta, en las que, además de su futuro, aprende el pasado de Eneas, lo ocurrido en los libros I-VI del poema, la hacen copartícipe de la recreación en diferido de su propia vida.

Con ello queda manifiesta su naturaleza fictiva, inserta en otra ficción dentro a su vez de una tercera. El propio Virgilio, abrumado por lo intrincado de estos marcos, los define como «[a] dream within a dream. . within the dream that has been my life. . .». «I am not a dream, and I don't think I'm dreaming» (41), contesta con serenidad Lavinia ${ }^{8}$, contrarrestando esta disonancia cognitiva y convenciendo al poeta por añadidura.

Seguidamente, la narrativa entronca con el flashforward del comienzo de la novela: la llegada de los troyanos. Tras una escalada de tensión, se desencadena una cruenta guerra por el Lacio, que termina con la muerte de Turno. Sin embargo, el final de la Eneida no supone el fin de la novela. Eneas y Lavinia se casan y fundan Lavinio (Lavinium); disfrutan de tres años de matrimonio y tienen un hijo, Silvio; tras la muerte de Eneas, se narran las vicisitudes de Lavinia y Silvio, con la amenaza latente de Ascanio y sus aspiraciones de poder. Finalmente, Lavinia, al morir, como si fuera ovidiana en vez de virgiliana, se transforma en lechuza.

La progresión lineal se ve ocasionalmente interrumpida por saltos prolépticos, la mayoría diálogos con Eneas. Los diferentes planos narrativos permiten al lector componer el encaje de los acontecimientos desde una doble perspectiva: la cerrada de la obra de Virgilio, y la abierta de una conciencia conocedora de la trama gracias a las visitas espectrales del poeta moribundo.

Haydock divide la novela en tres secciones: «Lavinia's Odyssey», «Lavinia's Iliad» y «After Virgil» (2018, 383). Para la relación con las fuentes clásicas y su tradición, véanse Cristóbal 2015; Cantó Llorca 2016; Walde 2019.

8 Byrne (2012) explora la ambigüedad metafictiva de estas conversaciones: «With these words, she stakes her claim to a more grounded and solid existence than the poet who has written her into the canon of Western literature» (6-7). 


\subsection{Conversando con Virgilio: figuras y procesos liminales}

A los doce años, Lavinia visita por primera vez con su padre el enclave sagrado de Albúnea (28), frontera liminal con el inframundo, lugar de encuentro entre los muertos y los vivos": Albúnea «lies so close to the underworld that the shadows of the dead can come and go there easily» (88). Durante esta experiencia iniciática, sueña con su bisabuelo Pico, transformado en pájaro carpintero. En un episodio febril de su infancia ya lo había visto en sueños, pero esta vez le roza los ojos con las alas: «He has opened your eyes to see» (31), «a deeply symbolic act [...] implying her newly granted ability to see beneath superficial reality» (Lindow 2009, 225). Además, Lavinia conoce las aves y los augurios, arte aprendido de una esclava etrusca (38), con cuya hija, Maruna, conversa sobre pájaros y muertos. Así, Lavinia está doblemente sensibilizada para los encuentros sobrenaturales venideros: «so that when I slept at Albunea that night [...] on that ground that is so thin a roof above the underworld, the poet could come to me and I could see and speak to him» (39).

La primera visita del poeta (39-49) se produce en abril, cuando ella tiene dieciocho años. Los encuentros son nocturnos, entre sombras y sueños. Lavinia ve «a tall shadow» ${ }^{10}(40)$, un espectro («a wraith») cuyo cuerpo no está allí, sino en un barco rumbo a Italia ${ }^{11}$. Virgilio se halla en varios trances liminales: mortalmente enfermo, navegando $\mathrm{y}$ en una suerte de viaje astral o de sueño febril («delirium», 43) que le permite franquear el umbral de su propia ficción ( «A dream that has flown into a dream. Into my poem», 41). Virgilio le explica a Lavinia que es un poeta; ella, que vive en una Italia preliteraria, no sabe el significado de la palabra; el suyo es un mundo de ritos, augurios y profecías: "'A vates,' he said. I knew that word of course, foreteller, soothsayer. It went with his being part Etruscan, and with the knowledge he seemed to have of what had not happened yet» (45). Su cercanía con lo sagrado, por ser hija del rey y sacerdotisa, la vincula con el poeta en su capacidad de anticipar y recrear la realidad. La religiosidad de Lavinia no solo demuestra su profundo sentido de la responsabilidad, como señala Behr $(2014,203)$, o es un reflejo realista del mundo primitivo de la novela, como aprecia Cristóbal $(2015,374-375)^{12}$, sino que también contribuye claramente a su liminalidad ${ }^{13}$. Sabe mediar entre mortales y divinidades mediante plegarias y sacrificios, y

Albunea es el lugar donde Latino se comunica con los muertos y recibe el oráculo de Fauno sobre el matrimonio de su hija (Verg.Aen.7.81-100). Le Guin ambienta fielmente en este pasaje el lugar y sus ritos. Sobre la Albúnea virgiliana, véase Horsfall 2000, 96-97.

10 La Vita Vergilii de Suetonio, transmitida por Donato, destaca la estatura del poeta, pero debe tenerse en cuenta, además, la altura sobrehumana de los fantasmas en el imaginario romano: Verg.Aen.2.773 (Rivero et al. 2009, ad loc.). Según Bugada $(2019,71)$, coinciden en esta descripción «dato biográfico y alusión a Creúsa». Lavinia confunde el espectro con un árbol, tal vez otro eco lejano de la Vita (la madre del poeta, embarazada, soñó que daba a luz una rama de laurel que al punto echaba raíces y se convertía en árbol maduro). La joven le indica dónde está y quién es ella, a preguntas del poeta, como suelen comenzar las conversaciones épicas entre forasteros y autóctonos. Cf. e.g. Verg.Aen.1.331-332; Hom.Od.13.232-233. Sobre el pasaje, Haydock 2018, 384.

11 El Virgilio de Le Guin tiene irisaciones de Dante y, sobre todo, de Broch (O’Hara 2010, 106; Miller 2010, 36; Cox 2001, 251, 254: «Le Guin [...] evoques Virgil's laments in Broch not only at his shame but also at his abiding sense of having always skirted around the edges of existence»; Cristóbal 2015, 369, 374; Haydock 2018 , 377; Teodoro Peris 2018, 215; Bugada 2019, 75-76).

12 Para la recreación de la religión arcaica de los latinos en la novela, véase Teodoro Peris 2019, 214-220.

13 Lavinia oficia los ritos familiares como ayudante de Latino (7, 18, 29, 89, 136, 172-173; cf. Verg.Aen.7.71-72) y cuida del fuego sagrado $(23,44)$. La suya no es una religión de caprichosos dioses antropomórficos (68-69), sino una comunicación con los «grandes poderes» de la naturaleza $(40,264)$. En varias ocasiones, de hecho, reflexiona sobre su rol liminal de intermediaria entre la divinidad y el pueblo: «a powerless girl, yet one who could 
vislumbrar el futuro mediante visiones ${ }^{14}$, augurios $(28)^{15}$ y señales: no es de extrañar, por ello, que pueda comunicarse con una sombra cuyo cuerpo está en trance de agonía, pero que ni siquiera ha nacido, una paradoja temporal sobre la que Lavinia reflexiona al final de su vida y al principio de la narración (10), entre otros pasajes ${ }^{16}$.

Pocas semanas después del primer encuentro, «in the evening of the Kalends of May» (53), Lavinia vuelve a Albúnea, donde su ánimo decae entre dudas: «I had had a dream about a man who was dying somewhere else, in some other time. Nothing to do with me» (53). Aún se resiste a creer en su ficcionalidad. Lavinia se queda dormida y cuando despierta -o tal vez lo sueña- se produce el segundo encuentro (53-63). Si en la primera conversación Virgilio le recitó la caída de Troya, en esta conversan sobre Dido y Eneas. La noche siguiente se produce la tercera visita (64-71), en la que hablan del inframundo y los dioses (libro VI), y de la estancia de los troyanos en Sicilia (libro V). La última (90-95) tiene lugar cuando Latino y su hija buscan en Albúnea una explicación para el omen del cabello ardiendo de Lavinia (84). Esa noche Virgilio relata la segunda parte de su poema, la vida aún no vivida por Lavinia: las guerras de Italia, el futuro inmediato de la joven ${ }^{17}$ y el tiempo limitado de Eneas $(94)^{18}$. La mitad de la Eneida se condensa en una breve conversación de seis páginas, porque el poeta se ha quedado sin tiempo. Al otro lado de los siglos, se está muriendo: «I join the crowd, return to darkness» (94). La vez anterior Lavinia pudo convocar de nuevo a la sombra evanescente (67), pero ahora intenta retenerlo en vano: «I cried out his name, went forward, reaching out my arms to hold him to keep him from death, but it was like holding a breath of the night wind. Nothing was there» (95). El poeta no va a volver, ya es definitivamente una sombra del inframundo. Los ecos de la Eneida, cuando Eneas trata de retener el fantasma de Creúsa (Verg. Aen.2.791-794) $)^{19}$, son la señal inequívoca.

speak for them to the great powers» (160); «we are go-betweens» (216). Curiosamente es una intermediación que solo puede realizar en el estatus transicional de no casada (220).

14 Lavinia tiene visiones premonitorias. En Albúnea ve las aguas del río Numico teñirse de rojo (30, 50-51), profecía cuyo sentido revelará Virgilio (94) y que se cumplirá con la muerte de Eneas (239). También ve la ciudad de Lavinio: «the city on a hill» (39), «'I saw it there, the city,' I said. 'In a dream'» (190).

15 Latino puede interpretar fehacientemente las señales divinas («omens») $(76,85)$. En cambio, Eneas, «guided by omens and oracles» (205), no tiene la capacidad interpretativa, pues su sentido ya le ha sido revelado con anterioridad $(103,249)$. Un omen mal interpretado puede tener consecuencias fatales $(175-176,178)$.

16 Virgilio es «a dying man who had not yet been born and who knew my past, my future and my soul» (83); cf. «my poet had known it [...], in the dark time to come, hundreds of years after I heard it sung» (219). Se atisba, por un lado, la pulsión especulativa de Le Guin (la posibilidad de que se produzca una paradoja del viaje en el tiempo) y, por otro, su emulación de la complejidad temporal de la Eneida: el presente de Lavinia es el pasado de su autor, que aún no ha nacido; en el poema épico el presente de Eneas es el pasado de la grandeza de Roma, objeto del encargo poético, pero que solo se vislumbra proyectado hacia el futuro.

17 La revelación onírica del futuro de Lavinia se confirma con el oráculo de Fauno a Latino (95), en contraste con el falso sueño de Amata, obsesionada con Turno: «Oh! The bridal bed! In Ardea! I saw it all in my dream!» (97). Al contrario que su hija, Amata fracasa en sus experiencias liminales, como en el ritual campestre femenino de naturaleza carnavalesca que prepara como paso previo a una boda semiclandestina con Turno (110-120; cf. Verg.Aen.7.385-405). Este rito de paso anómalo (Lavinia lo describe como «unreal, fantastic», 111; «unreal», 113; «the falseness, the insanity», 116) no tiene el desenlace deseado. Resulta fallido por la huida de Lavinia, cuyas potencialidades liminales la acercan a su padre Latino y la alejan de Amata (36). De hecho, Lavinia abandona la zona del palacio donde habitan las mujeres, exiliada por un tiempo en su propio hogar (136).

18 Verg.Aen.1.265-266.

19 Cf. Verg.Aen.6.700-702 (fantasma de Anquises). También hay ecos intratextuales: «And he tried to speak to her, and to take her in her arms-three times he tried, but it was like putting his arms around the wind. She was gone into the shadow» (49). 
Al final de la novela (266-268), Lavinia acude una vez más a Albúnea, con su hijo Silvio. Perdida desde la muerte de Eneas, sin control de su vida, invoca al poeta en su interior, pero no aparece. Dormida, tiene una visión del futuro de Silvio, la misma que Eneas en el inframundo (Verg.Aen.6.761-766), comentada por Anquises, que llama al nieto regem regumque parentem (Verg.Aen.6.765). Ella aprovecha esta visión para zafarse de la presión de Ascanio para llevarse a Silvio a Alba Longa (269-270), difundiéndola cual oráculo del propio Anquises. Pero no es la voz de Anquises la que ella oye en sueños, sino la del poeta: «It was the poet who spoke. It was all the words of the poet, the words of the maker, the foreteller, the truth teller» (271). Más allá de las cuatro ${ }^{20}$ visitas nocturnas, esa voz ha resonado siempre en su oído, solapándose con otras como las olas del mar, dando forma a su vida $(105 ; 123 ; 171 ; 222-223)$.

\subsection{Lavinia desde su atalaya}

Lavinia no solo aprende del poeta: también ve, escucha, espía a su alrededor. Para Cristóbal $(2015,369)$, su «experiencia autópsica y su bien manifestada curiosidad» están al servicio del cambio que se opera en la narración, de la heterodiegesis de la Eneida a la homodiegesis de Lavinia. Son innumerables las ocasiones en que Lavinia escucha o ve clandestinamente, costumbres impropias de su condición y sexo: «a girl, a king's daughter, a marriageable virgin, chaste, silent, obedient, ready to a man's will as a field in spring is ready for the plough» (5): la metáfora sexual y social radica justamente en su propensión epistemológica a la observación: «I've never ploughed, but I've watched our farmers at it all my life» (5).

Su lugar predilecto son las alturas ${ }^{21}$, a vista de pájaro. Ante la inminente llegada de Turno, sube a la atalaya, «from which one could see down into the streets and over the city walls and gate» (19). Desde esa posición estratégica puede ver más lejos que nadie en la distancia y otear los asuntos cotidianos (161), sin menoscabo de su seguridad (136-137). Pero también pasa desapercibida a ras de suelo y a la vista de todos, sin necesidad de ocultarse $(20 ; 105-107)$, una invisibilidad propia de los esclavos $(114)^{22}$.

Los enclaves liminales (las orillas del Tíber o los umbrales de las estancias de palacio $^{23}$ ) son fundamentales para conocer y conocerse. Según Gaylin, escuchar a escondidas añade complejidad a los umbrales entendidos como cronotopos, concepto bakhtiniano que designa «the intertwining of space and time, the primary categories of perceiving reality in its most specific immediacy [...] and establishes a metaphoric liminality» $(2004,16)$ dentro de ellos. En general, estas situaciones pertenecen al

\footnotetext{
No tres (Haydock 2018, 385; Teodoro Peris 2019, 215).

21 Cf. «watchtower» $(19,129,136,152,161,162,164,180)$, «tower» $(137)$, «roof» $(129,136,161,206)$, «platform» $(131,136,163,164)$, «parapet» $(137,161,163)$, «roof-parapet» (206) o «spy-post» (188). Se trata, en muchos pasajes, del motivo de la teichoskopia, recurrente en las obras clásicas ambientadas en la guerra (Provini 2014, 186; Fuhrer 2015; cf. e.g. Verg.Aen.11.475-476, 877; 12.132-133, 595, 705-706). Desde otro lugar elevado, una colina, Lavinia espía a los troyanos recién llegados $(102,152)$. Como señala Cristóbal (2015, 369), en la Eneida es Eneas quien sube a lugares altos para comprender lo que sucede a su alrededor. Cf. Verg. Aen.1.180; 2.302-303. También los dioses y la Fama observan desde lo alto (Verg.Aen.4.186-187 summi culmine tecti / turribus aut altis).

22 Su confianza y afecto hacia los esclavos $(50,117)$ también enfatizan su identidad liminal.

23 «She had not seen me standing just past the door» (146), confiesa refiriéndose a su madre, a quien sigue sigilosamente tras escuchar su discusión con su padre.
} 
ámbito doméstico de los esclavos ${ }^{24}$; al masculino, en forma de espionaje y estrategia militar; y al divino y espectral. Lavinia disfruta de un acceso transversal y liminal a estos tres contextos. En concreto, ver y oír con sigilo ${ }^{25}$ lo que solo ella parece ver y oír confiere a la narrativa un grado de omnisciencia selectiva sin una agencia externa que levante tejados o atraviese espesos muros. A la vez, le permite reflexionar, actuar y tomar decisiones rayanas en la venia autorial, divina o sobrenatural, por mucho que en último término estén sujetas a los lindes del poema.

\section{4. «That knowledge changed nothing»: a vueltas con el destino}

Una de las fuerzas motrices de la narrativa es la tensa incertidumbre de si Lavinia aprovechará lo que sabe por Virgilio para alterar el continuum de los hechos venideros $^{26}$. En retrospectiva, Lavinia se ciñe al poema y ninguna línea canónica resulta alterada $^{27}$. Varios pueden ser los motivos. Por un lado, le cuesta recordar las palabras del poeta o más bien se resiste a recordarlas (99); a veces las considera un mero sueño $(83)^{28}$. Por otro, las prolepsis (visiones, oráculos y augurios) prestan «a determinism to all that occurs» (Haydock 2018, 383), lo que dificulta cualquier alteración ${ }^{29}$. $\mathrm{Su}$ falta de voluntad para tomar otras sendas que las marcadas por Virgilio puede ser un reflejo de su «liminal status», en la medida en que posee, según Byrne, «a deferred presence where action is concerned, but is not permitted agency» $(2012,10)$. Virgilio tampoco puede cambiar la Eneida, como él mismo confiesa a su personaje ${ }^{30}$, ni Eneas su destino ${ }^{31}$.

Esta tensión entre determinismo y agencia es constante. En su primera visita, Virgilio vacila ${ }^{32}$ al hablarle a Lavinia sobre su futuro y su naturaleza fictiva: «How much is it right to tell you? Do you want to know your future, Lavinia?» (43), le

24 «Very little in a king's house can be a secret» (79); «There are always tale-bearers, toadies, among household slaves [...]. No room in a king's house is without an ear at the door» (81). Consciente por experiencia de que las paredes oyen y de la facilidad con que un secreto se vuelve un rumor incontrolable, los temores de Lavinia coluden con el intertexto virgiliano de la Fama del libro IV (Verg.Aen.4.173-218, 297-298, 665), que fagocita el plano privado y lo torna público con una dinámica expansiva cercana al contagio metafórico.

25 Este elemento («eavesdropping») es consustancial al género teatral, de donde parece haberlo tomado el novelístico (Gaylin 2004, 3-4).

26 «Lavinia [...] appears to possess two distinct voices of her own, the one deeply in love with the world Vergil has created for her, and the other equally desirous of traveling beyond its limitations» (Miller 2010, 30). Solo intenta engañar al destino en lo que se refiere a la muerte de Eneas («my efforts to deceive our fate», 213; cf. 221), pero es plenamente consciente del significado de la profecía.

27 Como ella misma indica con una imagen de costura, su labor es de zurcido, enmendando «those tiny rents in the great fabric» (151).

28 «False dreams, visions, follies» (83). A veces el sueño se distorsiona como en una pesadilla (115).

29 Por si fuera poco, consciente de su potencial polémico, Lavinia asume como propia la proverbial mutabilidad femenina, porque cree que conduce a una verdadera libertad frente a la rigidez masculina, inmutable y obcecada; de ahí que rehúya el resentimiento de, por ejemplo, la Penélope de Atwood (Haydock 2018, 384): «I am not the feminine voice you may have expected. Resentment is not what drives me to write my story» (71); según Miller, a este respecto, «Le Guin delivers a fairly orthodox reading of the great Latin epic» (2010, 29). Para Plate (2011, 148), «Lavinia models women's rewriting beyond distrust».

30 "'Who is it that permits or forbids you?' 'The Gods. My fate. My friends. Augustus'» (65).

31 «Not even need and love can defeat fate, Lavinia. Aeneas' gift is to know his fate, what he must do, and do it» (58).

32 Al hablar de Dido, el poeta titubea de nuevo: «The poet seemed hesitant» (56). 
pregunta con cautela. Su respuesta negativa no se compadece con su actitud en sucesivos encuentros: Lavinia sí quiere saber, aunque ese conocimiento no cambie nada, porque es a través de las palabras de Virgilio, del poema, como cobra vida. Para ella no es difícil, sino vital, por paradójico que parezca, creer en su ficcionalidad. No así para Eneas, a quien nunca desvela que viven en un poema (125-126) ${ }^{33}$ : «To know that he has obeyed a poet, rather than his conscience, might be anguish to him-even if he saw, as I see, that the poet obeyed his conscience and followed the fas» (126).

La liminalidad autoconsciente y fluida de Lavinia, su contingencia (71), le permite leer, ponderar e interpretar imaginativamente ${ }^{34}$-al contrario que su marido (Verg. Aen.8.730 rerumque ignarus) - el amplio abanico temporal que aparece enigmáticamente representado en el escudo de Eneas $^{35}$. Como en otras ocasiones, Lavinia no puede revelarle la fuente de su capacidad para descifrar el futuro vislumbrado en su escudo:

'I saw it. Call it in a dream' [...]

'You know how to read it,' he said thoughtfully. 'I never have.'

'Guesses, dreams' (209).

El escudo, y aquí está lo inquietante, representa el futuro hasta límites insospechados (submarinos, aviones y un hongo atómico: «I know it is the end of the world», 27), recurso propio del impulso especulativo de la ciencia ficción, el mismo que lleva a Battley, Gaiman, Atwood o Le Guin a proyectar hacia el futuro hipotéticos acontecimientos sin narrar, tanto como al pasado, reescribiendo o proponiendo alternativas y llenando huecos y vacíos (Brown 2012, 210).

Tras la muerte de Turno, Lavinia se lamenta con insinuados ecos dantescos de haber perdido a su guía, su Virgilio, y de que debe continuar, cambiar, trascender, «through all that is left after the end, all the rest of the immense, pathless, unreadable world» (183). Con el final de la Eneida comienza una senda propia y toma la iniciativa de adivinar, de abrirse paso en el laberinto ilegible de su vida, pero siempre con la guía, esta vez indirecta, de su poeta:

I have found my way so far, even though the poet did not tell me the way. I guessed it right, without mistake, from things he said, the clues he gave me. I came to the centre of the maze following him. Now I must find my way back out alone. It will be longer and slower in the living, but no so long, I think, to tell (183).

\section{5. «An owl flitting in the dark oaks of Albunea»: Lavinia como lechuza}

Lavinia comienza la novela explorando su liminalidad, puerta entreabierta hacia la inmortalidad: su vida ha sido

33 «Viewing the story from the margins affords her a greater perspective than that of Aeneas, who looks at his story from the centre» (Cox 2011, 258).

34 Haydock, en cambio, opina que su descripción por parte de Lavinia «highlights, like its Aeneid intertext, the incomprehensibility of the images pictured there» $(2018,382)$.

35 Verg.Aen. 8.625-731. 
too contingent to lead to anything so absolute as death. I have not enough real mortality. No doubt I will eventually fade away and be lost in oblivion, as I would have done long ago if the poet hadn't summoned me into existence. Perhaps I will become a false dream clinging like a bat to the underside of the leaves of the tree at the gate of the underworld, or an owl flitting in the dark oaks of Albunea (3-4) ${ }^{36}$.

A diferencia de Virgilio, ella no tiene que desgarrarse de la vida. En su lugar, ha asumido una existencia más auténtica que la que proporciona morar en el inframundo

waiting to be forgotten or reborn - that isn't true being, not even half-true as my being is as I write and you read it, and nowhere near as true as in his words, the splendid, vivid words I've lived in for centuries (4).

En esta alusión a murciélagos y lechuzas se ha visto una respuesta velada a The Penelopiad de Margaret Atwood: Penélope comienza su historia advirtiendo desde el inframundo a sus lectoras que no sigan su ejemplo, pero solo le sale el canto de una lechuza ${ }^{37}$. Sin embargo, la imagen de la lechuza no es un mero guiño a la autora canadiense, sino un elemento clave en la caracterización de Lavinia.

Durante las nocturnas visitas espectrales, se oyen lechuzas que parecen conversar, como Virgilio y Lavinia (43 bis, 53, 90): la sombra del poeta moribundo reconoce ese familiar chirrido que le retrotrae a su Italia: «the owls call, [...] this is Italy, I'm home!» (43). El canto retorna en la invocación final en Albúnea, esta vez muy lejano: «an owl called once, from the right, far away up on the hillside, a long quavering $i-i-i \gg(266)$. No cabe duda de que la lechuza, que habita invisible entre los humanos, es un poderoso símbolo del conocimiento trascendente y la relación con el poeta.

La lechuza aparece en otros momentos cruciales. Su chirrido es la señal convenida con Maruna para escapar en mitad de la noche del ritual carnavalesco que Amata ha preparado para casar a su hija con Turno (120). La rapaz nocturna, oída en la duermevela, representa lo que separa la conciencia del sueño y sirve de transición, de vía de escape.

Más tarde Seresto, uno de los troyanos, cuenta que vio una lechuza atacar a Turno durante su lucha con Eneas, a plena luz del día, lo que crea un halo de extrañamiento, «an uncanny thing» (184). De no tener en cuenta el hipertexto virgiliano ${ }^{38}$, podría interpretarse que aquí Lavinia hace doble acto de presencia tanto en diferido como por anticipación; el tiempo y el espacio no suponen un obstáculo para quien sabe sobrevolarlos. Sin embargo, cuando rememora este detalle con Eneas, la versión di-

36 Sobre los sueños falsos adheridos al envés de las hojas de un olmo en el inframundo, cf. Verg.Aen.6.282-284 (Horsfall 2013, vol. 2, 243-245).

37 Miller $(2010,30)$ encuentra otro paralelismo con el final de la novela de Atwood: «The Maids sprout feathers, and fly away as owls (109)». Penélope se lamenta al principio del relato de que los pocos que pueden oírla desde la otra orilla del río, los vivos, confunden sus siseos con el viento o los sonidos de los murciélagos, una imagen que, además de Lavinia, también emplea el personaje de Virgilio (41; cf. Hom.Od.24.6; más pasajes en Horsfall 2013, vol. 2, 231).

38 Cf. Verg.Aen.12.861-868. Este es prácticamente el único pasaje bélico con agencia sobrehumana en Lavinia; al contrario que Virgilio, Le Guin dibuja un conflicto de proporciones humanas, sin intervención divina (Provini 2014, 88-90). Las naves troyanas no se salvan convirtiéndose en ninfas (141, 147; cf. Verg.Aen.9.77-122; 10.215-259) ni Venus interviene para curar a su hijo (Verg.Aen.12.411-424). Por ello resulta llamativo que se conserve este detalle de la Eneida, eliminando la agencia divina. No se trata de una furia enviada por Júpiter, sino de una presencia inexplicable. 
fiere: Seresto dudaba de si había visto a la lechuza de verdad o a Turno imaginando algo «that wasn't actually there» (198). Además de la muerte inminente ${ }^{39}$ de Turno, la lechuza simboliza los límites difusos entre realidad e imaginación, en los que transita Lavinia ${ }^{40}$. La libertad y la agencia de Lavinia-lechuza contrastan con la imagen de la paloma atada a un palo (45; 107; cf. Verg.Aen.5.488-489), relacionada con el cortejo de Turno ${ }^{41}$. Prometida a Eneas, sabe por primera vez «what it would be to fly, to take on my wings across the years, to go, to go on» $(107)^{42}$.

La querencia de Lavinia por los cronotopos elevados, ya mencionada, y por la naturaleza ${ }^{43}$, su nocturnidad ${ }^{44}$ y su sigilosa observación anticipan su transformación en una pequeña lechuza que observa inadvertidamente desde los olmos ${ }^{45}$, aletea por un tiempo en flujo perpetuo y domina la escritura. El círculo se cierra al cumplirse su augurio con su muerte ${ }^{46}$ en las páginas finales. La voz de Lavinia es la de la lechuza, cuya alma solo a veces «wakes up as a woman again» y oye el silencio de las páginas cerradas, «and in the silence his voice» (287).

\section{6. «Tell me I can finish my work!»: liminalidad y (re-)creación}

La cualidad liminal de Lavinia, su intermediación entre diferentes mundos, su capacidad para conocer e interpretar, su transmutación en «a bodiless voice» (72) la acercan a su poeta creador: «we were talking with such ease and openness, in perfect trust, as if we were both shadows, harmless and invulnerable, with all eternity before us» (46). A lo largo de sus encuentros con la sombra de Virgilio, de las conversaciones sobre la insatisfacción del poeta con el resultado del poema $(54,61,62)$, se desvela que es precisamente ese carácter inconcluso de la propia obra lo que les permite a poeta y criatura vivir eternamente en ella, habitarla en un permanente acto de reescritura: «I have been granted what few poets are granted. Maybe it's because I haven't finished the poem. So I can still live in it, be here - be here to talk to me me, even if I can't write. Tell me, daughter of King Latinus, how goes it in Latium?» (54). Con esta invocación, Lavinia se convierte en musa, inspiradora, creadora de un nuevo canto que se superpone al anterior, que lo continúa sin apartarse de él, en

39 Para las rapaces nocturnas como aves de mal agüero, véase Librán 2014, 89-92.

40 Cox $(2011,250-251)$ llama la atención sobre el «dreamworld» de la novela, donde se difuminan los límites entre realidad e imaginación.

41 No es la única imagen aviar relacionada con la libertad: de camino a Albúnea, Lavinia se siente como un gorrión liberado (99).

42 Palabras que reaparecen al final de la novela: «i, $i$, I cry: go on» (287). Su transformación se anticipa en otros pasajes: cf. «If I never lived at all, yet I am a silent wing on the wind, a bodiless voice in the forest of Albunea. I speak, but all I can say is: go, go on» (72).

43 Su amor por el campo y la vida agreste es evidente en su infancia $(15 ; 31 ; 38)$ y viudedad, y Albúnea, siempre un lugar de escape y libertad. Si en Alba Longa, con Ascanio, se ha sentido exiliada (245), no es así en absoluto criando a su hijo en el entorno de Albúnea (261-283) («no exile at all», 272). Que Lavinia se despida de la vida humana en ese enclave es una consecuencia natural de la narración.

44 Muchos momentos de revelación ocurren mientras los demás duermen («No one was awake», 2; «they were just waking», 96).

45 Aunque puede relacionarse con otras transformaciones en ave (Byrne 2012, 16 ve un paralelismo con la metamorfosis de Filomela, por ejemplo), la suya le viene de familia, pues la metamorfosis de su bisabuelo Pico en pájaro carpintero es un recuerdo constante («my grandfather the woodpecker flew to me», 6). Lavinia se identifica con otro significativo animal, la loba: «she-wolf» (50); «Mother-wolf» (272).

46 Miller 2010, 46; Byrne 2012, 16; Bugada 2019, 73-74, 76. 
permanente diálogo: Lavinia existe como novela precisamente porque el personaje no se desarrolla en la Eneida y porque el poema (su poema) está la vez «finished»y «left unfinished» (182):

'Wait -only tell me- your poem, my poem, did you finish it?'

He seemed to nod, but I could hardly see him, a tall shadow in shadows (94).

Poema y novela dialogan en interminable recursividad o mise en abîme: Lavinia sueña a Virgilio, que a su vez la sueña a ella, que lo sueña a él... y, recuérdese, tal vez ambos son «a false dream» $(4,41)$. La indeterminación recurrente entre realidad e imaginación, junto con la ambientación onírica de la novela, enmarcan ese acto de permanente reescritura. Lavinia, en su liminalidad, simboliza el acto de creación poética -plenitud e insatisfacción-, lo acabado y lo inacabado.

\section{El silbido del arquero de Irene Vallejo}

El silbido del arquero (2015), segunda novela de Irene Vallejo, recrea la relación entre Eneas y Elisa ${ }^{47}$, junto con un lance imaginado de la vida de Virgilio. En los capítulos impares ${ }^{48}$ cuatro personajes cuentan su versión de la historia: Eneas, Elisa, Ana y Eros. Cada subcapítulo está encabezado por el personaje que narra en primera persona $^{49}$ y tiempo presente. Entremezclada con esta polifonía de voces, a veces disonantes en la interpretación de los acontecimientos, aparece en los capítulos pares ${ }^{50}$ una narración en tercera persona, que describe el sufrimiento de Virgilio ante la mole del encargo poético de Augusto. Solo en el capítulo VII se une el poeta al resto de narradores en primera persona con voz propia y traspasa la barrera del tiempo para interactuar en vano con ellos, con Eros como testigo. El capítulo VIII, «Detened las aguas del olvido» (207), es un melancólico epílogo a cargo del dios del amor.

Eneas y Elisa habitan el mundo de la leyenda y la historia imaginada, mientras que Eros y Virgilio reciben sus propios marcos narrativos, a través de los cuales interactúan con los personajes. Ana, sin embargo, es un puente entre los dos mundos, entre muchos mundos, y como trasunto del poeta, reflejo metaliterario del trance de la creación poética.

\subsection{Ana en El silbido del arquero}

Tras el naufragio de los troyanos, contado por Eneas ${ }^{51}$, con vívidos ecos del libro I de la Eneida, una voz distinta toma la palabra: «Decían que mi madre era una bruja. Ana, la hija de la hechicera, me llamaban. Ana, la hija bastarda del rey de Tiro» (12).

\footnotetext{
En la obra no aparece la denominación libia Dido, sino el nombre original fenicio Elisa. «Naufragio», «Sangre», «Amor», «Asedio».

Ana emplea también la segunda persona, hablando a Yulo, que apenas tiene voz propia en la novela. «Sombras iban delgadas», «Una tierra bajo otro sol», «Si algún poder tiene mi canto». Cf. Verg.Georg.4.472 umbrae ibant tenues; Georg.2.512 alio patriam quaerunt sub sole iacentem; Aen.9.446 si quid mea carmina possunt.

51 Lavinia y El silbido del arquero comienzan con la llegada de Eneas al lugar del relato, como las dos partes de la Eneida.
} 
Para los lectores de la Eneida, Ana es un personaje familiar: hermana de Dido, la anima a deponer su castidad de viuda, la acompaña en rituales, media entre ella y Eneas, y llora desconsolada su muerte, contribuyendo, junto con otros elementos, a la cualidad trágica del libro IV $^{52}$. Aquí, sin embargo, su rol es diferente, los datos de su vida distintos ${ }^{53}$ y su protagonismo, mayor: es, junto con Eneas, el personaje que más capítulos recibe.

Es hija ilegítima de un rey y de una bruja, hecho que la «mancha de nacimiento que le marca la cara» (97) parece revelar, acusadora y simbólica como un estigma ${ }^{54}$. Ana pertenece a dos mundos y no encaja en ninguno: su anhelo es que el agua del mar, al que recurrentemente dirige sus pasos, borre esas identidades con las que no se identifica (12).

Este no pertenecer a ningún lugar y estar a la vez presente en muchos y a medio camino de todos la convierte en motor de la trama: es la primera que ve a los troyanos náufragos, como la Lavinia de Le Guin; se mueve con sigilo, ve y escucha, y lo aprendido en secreto lo revela a su hermana la reina. Ve sin ser vista, igual que Lavinia ${ }^{55}$, como una "lechuza":

Soy silenciosa y ágil. Cuento a Elisa lo que veo y escucho, y ella me llama su pequeña lechuza, porque todo lo miro. [...] Voy de un sitio a otro con los ojos muy abiertos. Lo hago porque siempre me ha gustado saber lo escondido [...].

El tiempo es largo mientras espero el viaje que me llevará a una costa mejor [...]. Un día navegaré muy lejos para encontrar un país sin palacios, donde la gente no sepa lo que es la traición (13).

Su primera aparición supone una carta de presentación de los principios que la definen: junto con su ambivalente origen y su sigilo, el mar y el viaje ocupan un lugar prominente. La orilla, lugar donde se unen sin mezclarse el mar y la tierra, representa sus anhelos de una vida mejor, de escapar a un lugar utópico, pero también otorga al personaje una cualidad liminal palpable en otras facetas. Todos estos elementos se irán desplegando en espiral y se convertirán en fuertes vínculos con el poeta.

\subsection{Ana, entre el palacio y la calle}

El lugar de Ana está en el palacio de su medio hermana solo en parte. A menudo recorre Cartago como una flâneuse, confundiéndose entre la gente humilde, con la que comparte sus orígenes, y percibe los olores y la mezcla abigarrada de fuertes esencias de la vida (28). Escondida entre el gentío escucha por primera vez a Eneas, el «hombre vestido de lobo» $(25)^{56}$. Más adelante acompaña al niño Yulo por estos vagabundeos plebeyos y le explica, como guía de otro mundo, sus misterios (75). Pero también de ese mundo se verá excluida (152-153).

\footnotetext{
Para Ana en la Eneida, véase Pease 1967, 49-50.

53 Nada se decía en la Eneida sobre su edad o su cuna.

54 Hechicera y partera, entre otros menesteres de intermediación con otros mundos, la madre es un recuerdo permanente, fuente de conocimiento y crecimiento personal.

55 También Lavinia revela información a Latino, como una espía (2).

56 En la Eneida es el héroe quien escucha a sus compañeros de incógnito, oculto por una nube divina: Verg. Aen.1.412-413, 439-440, 516.
} 
En el palacio también está entre dos aguas: durante el banquete divide su oído entre el relato de Eneas y los murmullos que recelan del extranjero, los sonoros sorbos, las «risas sofocadas» (44), los eructos, los insultos y las bravuconadas que socavan su heroicidad (43-47). Su capacidad de ocultación y de escucha atenta a cuanto ocurre a su alrededor ${ }^{57}$ la convierten en pieza clave de la trama. Entre los originales añadidos de Vallejo se encuentran las maquinaciones palaciegas y los misteriosos asesinatos de los miembros del Consejo de la reina. Escondida en una vasija mientras juega al escondite con Yulo, Ana escucha fortuitamente ${ }^{58}$ una conversación clandestina en la que Malco el Escudo encarga la muerte de Eneas a un desconocido y se confiesa autor de los crímenes (166). La revelación de Ana a Elisa desencadena la venganza de la reina (186-191).

\subsection{Ana, entre los niños y los adultos}

Ana ha crecido entre adultos, rechazada y estigmatizada por otros niños en Tiro (98). Cartago, en cambio, es un lugar casi distópico, sin niños ni viejos, donde «nadie juega, nadie cuenta leyendas junto a la hoguera» (28), lo que supone una ausencia anómala de rituales necesarios para que perduren la estructura social y la identidad comunitaria. Ana rememora las veces que acompañó a su madre a partos difíciles ${ }^{59} \mathrm{y}$ su muerte dando a luz (97). Por eso sabe que los gritos que provienen de una cárcel cercana son de una parturienta y que el niño ha nacido muerto, en una ciudad maldita donde nadie engendra más que rumores: «Aquí huele a muerte» $(97)^{60}$. Cartago está enferma y nadie mejor que ella para diagnosticar el mal que la aqueja:

Por eso los que viven aquí pierden los dientes. Por eso los árboles se secan y dejan de dar frutos. [...] hay horribles plagas de escorpiones que salen de todas partes e invaden las casas, las calles, los campos. Por eso los únicos niños somos tú y yo. Las mujeres de esta ciudad son estériles, aquí no nacen niños (138).

La llegada de Yulo a la ciudad sin niños tiene efectos profundamente transformadores, que Elisa percibe: «se ha vuelto más infantil, más inocente, más aniñada incluso en su manera de hablar» (98). Elisa solo ve su inocencia, ajena a los signa amoris (99-100): «Ella no se da cuenta, pero mi sonrisa tiembla» (100). Sin embargo, Ana sí repara en el temblor y conoce su causa ${ }^{61}$ : «Así temblaban las mujeres que venían a buscar filtros y conjuros amorosos a la casa de mi madre» (100). Sabe de los afanes eróticos de los mayores, por haber sido muda voyeuse involuntaria de los encuentros sexuales de sus padres. A Ana, siempre oculta, al acecho, le gusta enterarse «de lo que hablan los mayores cuando corren los cerrojos» (101). Tras la unión de Elisa y Eneas en la cueva, la niña intuye que «algo nuevo les une» (128), secreto conocimiento que la acerca a su contrapartida en la Eneida, confidente y tercera.

57 Cf. «aguzo el oído para saber» (42), «escucho» (127).

58 En casos como este, «the eavesdropper often represents a "moral" authority; his or her acquisition of knowledge, and with it, narrative agency, can result in the restoration of stability, order, or narrative closure» (Gaylin 2004, 16).

59 «Cuando las mujeres echan un niño afuera, gritan muchísimo. Se retuercen y se estiran de dolor. Aúllan» (95).

60 Abortos y bebés muertos aparecen también de manera recurrente y simbólica en Lavinia $(53,64,241)$.

61 También Lavinia se percata de que su madre está enamorada de Turno (36). 
Acomplejada por su feo rostro y desgarbada figura, en transición hacia un cuerpo adulto (25), quiere demorar el edén de la infancia recobrada con Yulo, mientras experimenta, entre el horror y la vergüenza, los cambios de la pubertad: «No voy a crecer más. Ahora que por primera vez tengo un amigo, quiero que seamos niños» (125): «Esta tarde me duelen mis pequeños pechos puntiagudos, y siento vergüenza [...]. Yulo es mi único amigo, el único que no se ríe de mis pechos pequeños y doloridos» (136-137). La menarquia, miedo recurrente (25), pondrá fin a la infancia y la incorporará sin remedio a un mundo de adultos en el que las mujeres pierden la libertad y la palabra $(125)^{62}$.

La infancia es permanente transformación, y los niños comparten los cambios de sus cuerpos (137) y sus secretos: Ana le revela a Yulo el enigma de Cartago (138) y el niño trata de contarle, sin éxito, con balbuceos, el misterio de su padre (138-139). Con paciencia de maestra Ana enseña al pequeño troyano las palabras de su lengua y el arcano de la escritura, también aprendido de su madre, la hechicera fenicia (154). Con esas letras con las que se puede decir lo que se quiera «sin abrir la boca», Yulo por fin puede desvelar el secreto sin pronunciarlo: «Eneas. Hijo. Diosa-leo» ${ }^{63}$.

\subsection{Ana y las palabras}

La segunda vez que Ana ve a los extranjeros troyanos está escondida entre la muchedumbre, pero, a diferencia de ellos, ella sí comprende la conversación de Elisa y Eneas: «Habla en la lengua de los reyes sobre traiciones y huidas» (25). Su conocimiento de la lengua de los acadios la incluye en esa burbuja comunicativa, que el dios Eros trata de aprovechar $(40-41,90)$. Para Eneas y Elisa la comunicación interlingüística es una herramienta de seducción y de poder, y por ello ejercen de intérpretes de buena gana $(27,46,101)$, pero para Ana es un don peligroso. En el famoso banquete donde Eneas cuenta a la reina la caída de Troya y su huida, los miembros del Consejo de Elisa no callan atentos ${ }^{64}$. Cuando uno pide a Ana que repita sus bravuconadas «en la lengua del extranjero» (46), ella siente un miedo atroz y declina hacer de intérprete («No quiero que salgan de mi boca sus venenos», 46). La naturalidad con la que parece desenvolverse en el mundo adulto (32) desaparece ante el miedo: «mi voz ha huido como un animal asustado» (46).

Está en tierra de nadie a la par que sabe de todos más que nadie, pero no solo su inadaptación cronotópica y su cauto silencio le confieren un estatus liminal comparable al de Lavinia ${ }^{65}$, sino también su potencial como mediadora interlingüística, que reconoce las lenguas de unos y otros como mutuamente ininteligibles. No es el caso de Lavinia, quien se sorprende de que todos los personajes, ella misma e incluso sus lectores hablen y lean latín (5), en una reflexión que cimienta el carácter metafictivo de la novela ${ }^{66}$. En eso también se diferencia de Elisa, para quien la lengua de Eneas

62 La sola idea de casarse aterroriza a Ana. El símil del «caballo al que conducen tirando de la brida» (125) recuerda al de la paloma atada al poste de Lavinia. Para Lavinia el matrimonio es como un exilio (44), aunque su visión cambia una vez que se casa con Eneas (194).

63 En Lavinia la ascendencia divina del héroe también es tabú (232).

64 Verg.Aen.2.1.

65 Coinciden también en su afinidad con los extranjeros troyanos, que las enajena de los suyos. De hecho, Lavinia se siente traidora (142) en la guerra entre latinos y troyanos.

66 En Lavinia, para asombro de su propia protagonista, todos hablan latín (5). Troyanos y latinos se entienden; el poeta y su creación conversan como si la lengua del Lacio no hubiera evolucionado con los siglos (43); y la 
es un muro (136), indicio de que no puede escrutar en su interior, «un mar vedado» (136). Yulo y Ana también tienen una lingua franca con la que comunicarse: la de los niños, la de los juegos. Para Ana el habla de Yulo es un trabalenguas (74-75), pero la lengua no los separa porque en seguida ella se apresta a la tarea de enseñarle su idioma. La única comunicación no fallida en la novela es la de los niños.

En la Eneida la Fama aparece de repente y se convierte rauda en un monstruo repulsivo (Verg.Aen.4.173-218). Aquí, en cambio, aunque también crece desbocada, la maledicencia está latente desde el principio. Ana aplaca al pueblo inicialmente (27), pero más tarde percibe con terror creciente las voces discordantes y la rápida teratogénesis de la Fama. Tras el encuentro sexual en la cueva, descubrimos gracias a ella que «corren rumores» sobre Eneas (127), que «los ojos de la muchedumbre le vigilan», como los de la alegoría virgiliana (tot uigiles oculi ${ }^{67}$ ). La multitud no sabe, pero habla y va gestando al monstruo; los guerreros y consejeros murmuran. Ana escucha, sabe y calla: «Hay muchas cosas que yo sé, pero guardo el secreto en silencio igual que si un buey me estuviera pisando la lengua» (127). La imagen del buey sobre su lengua, tomada del Agamenón de Esquilo (36), en alusión a la relación de Eneas y Elisa ${ }^{68}$, no solo simboliza el silencio forzado que rodea los actos de los poderosos, sino que también anticipa desenlaces aciagos.

\subsection{Ana, entre los dioses y los mortales}

Mientras observa el sacrificio celebrado a su llegada, Eneas se figura que la niña que lo oficia -aún no sabe su nombre y se refiere a ella por la marca de su cara- es un puente entre mortales y dioses, «un túnel al cielo, o una copa donde los dioses se vierten» (30). Pero Ana, nombrada por la reina «sacerdotisa-niña de Eshmún»y «adivina» (26) desconfía de su capacidad de ejercer esa mediación: «¿me creerán si hablo en nombre de los dioses? ¿O se burlarán y lanzarán piedras contra mí?» (26). De hecho, fracasa como intermediaria entre dioses y mortales: su vaca, renuente, se resiste al sacrificio, pésimo augurio; sus entrañas, además, «presagian desdichas» (127), malos auspicios que olvida mientras juega con Yulo en la playa, en la elación del descubrimiento del misterio de Eneas. La esperanza le lleva al espejismo de un feliz augurio divino: «Eneas nos sacará de aquí y nos llevará de viaje por todos los horizontes del mundo. [...] Y mis pensamientos se deslizan como un sueño, revoloteando mar adentro» (155).

Su confusión alisa el terreno para la irónica y trágica fatalidad del episodio en que cita a Eneas en el Templo de Eshmún con la intención de convencerlo de que la lleve junto con su hermana lejos de Cartago: «En este oráculo de los dioses, del que yo seré mensajera, anida toda mi esperanza» (175). El momento elegido es doblemente liminal: el alba y el plenilunio. Mediante una droga que ha preparado, ambos entrarán en el trance que facilitará la comunicación. En dos capítulos contiguos (174-177; 177-181) cada personaje cuenta su versión del oráculo, pero las piezas no encajan.

protagonista-narradora se dirige a sus lectores del futuro en esa misma lingua franca, aunque en realidad lo haga en la lingua franca de nuestro tiempo, o en las lenguas a las que la novela se traduce: cualquier idioma, menos latín.

67 Verg.Aen. 4.182.

68 En la tragedia lo silenciado es el adulterio de la reina Clitemnestra con Egisto. 
Eneas afirma que ha entendido el mensaje divino (176): el trance místico de la niña ${ }^{69}$ lo convence de que habla por su boca un dios; la alusión a Venus, secreto que Ana conoce gracias a Yulo, es para él la señal clara del origen divino del mensaje. Como suele suceder con los oráculos, las ambiguas palabras pronunciadas por Ana, repetidas en su literalidad por Eneas, son interpretadas en un sentido errado (178): toma la decisión de huir solo con los suyos. No ha calado en él el suplicante anhelo de la muchacha.

\subsection{Mar adentro}

Ana y Elisa llegaron por mar a su nueva patria, huyendo de Tiro. El mar representa la huida, la salvación, pero también el peligro: contemplando el naufragio de los troyanos, Ana teme que sean siniestros enviados de su hermanastro Pigmalión (14) ${ }^{70}$. Ana no se siente segura en Cartago; necesita huir y «buscar un lugar tranquilo donde vivir de manera sencilla y buena», no tierra adentro, sino cruzando el mar: «Tengo que zarpar lejos de aquí, pero no sé adónde» (45).

La playa ofrece a Ana y Yulo un espacio de libertad, donde juegan y aprenden a comunicarse, un locus amoenus como el Lacio en tiempos de paz para Lavinia ${ }^{71}$. Este edén idílico se resquebraja: Ana escucha ruido de caballos; se adentra con el niño en el mar, lo protege con su cuerpo y así huyen del peligro (76), en un pasaje fundamental para entender el fino y fuerte hilo que une a Ana con Virgilio. El mar es, de nuevo, espacio de salvación. Yulo también siente querencia por el piélago: acude a la playa en busca de refugio y es ahí donde Ana le enseña las letras, entretenimiento y consuelo, pero irónicamente la brisa del mar también se lleva sus deseos, «revoloteando mar adentro» (155), donde se unen a las letras con las que Yulo confiesa el secreto de su padre, borradas por las olas (156).

Cuando los troyanos se marchen, el mar separará a los niños, pero Yulo está convencido de que Ana irá a buscarlo (194) y le deja un barquito de corcho y un mensaje en su escritura recién aprendida (201). «Recorreré Italia y daré contigo» (201), responde Ana. Entonces percibe los gritos de la guerra, Yarbas está en Cartago: ensimismada en su frustración, solo ahora empieza a percibir las dimensiones del desastre. De camino a la ciudad se cruza con el caballo blanco de Elisa, que herido se dirige al mar, poderoso símbolo de la libertad, de la guerra ${ }^{72}$ y de la muerte (202).

\subsection{Ana y Virgilio}

Al contrario que Lavinia, Ana no sabe de su ficcionalidad: sueña, pero no es consciente de ser parte de un sueño. Virgilio no se le presenta en sueños para hablar con su creatura. No obstante, sí hay un diálogo permanente e implícito entre creador y creación, que se manifiesta con fuerza y trasciende las concomitancias vitales entre ambos personajes a lo largo del relato.

\footnotetext{
69 Ya antes en una ocasión similar Ana había acertado en sus palabras adivinatorias (32).

70 Pigmalión la perseguirá, de hecho, cuando abandone Cartago, según otras fuentes (Ov.Fast.3.565-580; Sil.8.6070).

71 El campo como lugar seguro y espacio de libertad infantil es un motivo recurrente en la novela de Le Guin, relacionado con la Edad de Oro: 12, 17 («Then we were both Saturn's children»), 31-33, 81.

72 Verg.Aen.3.540.
} 
En el capítulo «Sombras iban delgadas», Virgilio se siente perseguido en Roma. Como Ana, «intenta confundirse con la muchedumbre» (61), pero no lo consigue: «Su gran estatura, los movimientos desgarbados, el aspecto campesino, permiten reconocerle a distancia y, por tanto, vigilarle cómodamente» $(61)^{73}$. Para Ana, Cartago es una ciudad maldita, infecunda y hostil; a Virgilio «Roma siempre le ha parecido una ciudad siniestra, un pozo de corrupción» (61). En Cartago no nacen niños; en Roma no se escriben poemas. Ambos son forasteros que preferirían estar en otro lugar. La Roma de la novela no es la idealizada del imaginario occidental, sino la urbe vocinglera y caótica, sucia, maloliente, esclavizadora, la ciudad de los epigramas de Marcial, las sátiras de Juvenal, y algunas cartas de Séneca. No hay poesía en su vagabundeo urbano: hay clientes camino de la humillante salutatio, letrinas donde desahogarse de los males del vientre ${ }^{74}$, pordioseros charlatanes, perros sin dueño, calles estrechas con hedor a orín, crueles maestros de escuela, admiradores incómodos... nada invita a la poesía. Virgilio no se siente capaz de poetizar las grandezas de Augusto: su vagar sin rumbo refleja su bloqueo creativo. La inspiración solo llega cuando piensa «en la orilla de Cartago batida por las olas [...], en las espumas del canoso oleaje, en los sueños que forjan los que aman, en las manos de Elisa» (69). Vislumbramos así que las palabras, sufrimientos, dudas $\mathrm{y}$ anhelos de los protagonistas son las ensoñaciones y elucubraciones de Virgilio. El mismo mar en el que Ana cifra todas sus esperanzas es la única fuente de inspiración del poeta.

En el segundo capítulo dedicado al Mantuano, «Una tierra bajo otro sol», mientras huye de un desconocido, retorna con su imaginación al pasado, a la naturaleza, a las enseñanzas de su padre. Recuerda cómo los años de escuela lo separaron de su aldea y de una niña celta con la que jugaba «a ser caballos, al escondite, a subir a los árboles, a buscar nidos, a dar de comer a los animales» (112), los mismos juegos de Ana y Yulo ${ }^{75}$. «Hablaban poco, apenas conocían unas cuantas palabras el uno en la lengua del otro. Él era solo un niño, pero a ella le despuntaban ya bajo la túnica unos pechos pequeños y puntiagudos» $(112)^{76}$. La infancia aldeana de Virgilio cimienta la entrañable historia de la adolescente sidonia y el niño troyano, a los que unas palabras bastan para comunicarse felices. Y descubrimos aquí que el lance de Ana protegiendo a Yulo en el mar está hilado con los mismos recuerdos y las mismas palabras de la traumática vivencia del poeta niño (112-113).

Como Ana, Virgilio no pertenece a ningún lugar: escribe poemas de campo que no leen los campesinos; aborrece la violencia, pero tiene que escribir un poema épico; odia el poder, pero se siente despreciado por los humildes (115). Vive en la insatisfacción vital y, como Ana, en el miedo, el que le provoca su desconocido perseguidor. Como mecanismo de defensa, Virgilio imagina «que cambia la antigua leyenda», que «Eneas no desembarca en Italia porque se queda con Elisa para siempre», lo que genera una cadena de consecuencias y paradojas históricas que hacen que pueda «escribir sus versos libremente» y nadie le espere «a la salida de una taberna para vengarse con crueldad» (116). Las experiencias y percepciones de

\footnotetext{
La descripción de Virgilio en la novela se corresponde con la Vita de Suetonio-Donato. Cf. Vit.Verg.8.

74 Cf. Vit.Verg.8.

75 «A ser caballos, a los palacios de arena, al escondite, a subir a los árboles, a buscar nidos y conchas y tortugas, a las figuritas de barro, a dar de comer a los perros...» (98). Juegos infantiles atemporales, pero preñados de simbología: libertad, naturaleza, lo sencillo, efímero y maleable de la arena y el barro.

76 Cf. 136.
} 
Virgilio, angustiado y errabundo, evocan la trama detectivesca del palacio de Elisa, al tiempo que se funden con las de Yulo por las calles de Cartago, contadas por Ana, en dos pasajes prácticamente idénticos $(152,167)$.

Virgilio desea abandonar la realidad que lo oprime, y, como Ana, surcar el mar, pero en sentido inverso, surcar el tiempo y encontrarse con sus personajes: «navegar a través de los mares y los siglos hasta las costas africanas, y, una vez allí, anudar entorno a Elisa y Eneas un hilo que ni el más afilado de los aceros pudiera cortar» (173). Pero ni Ana ni Virgilio conseguirán mantener unidos a los amantes. Ana sueña con dejar atrás Cartago, pero su deseo es un sueño dentro de un sueño.

En el capítulo VII, Eros conduce a una enloquecida Elisa al puerto, donde Eneas se apresta a zarpar. Para sorpresa del dios, junto a los amantes se encuentra «la figura extrañamente familiar de un hombre de tez morena y gran estatura que les mira desde el borde mismo del muelle, a unos pasos del mar, con ojos de triste intensidad» (183). Virgilio ha surcado el mar y el tiempo, percibe la presencia de Eros y juntos, dos seres divinos, contemplan la escena sin ser vistos. Por fin, rotas las ataduras de lo real, el poeta cumple su deseo de ser invisible como Ana. La escena tiene lugar al borde del mar, el lugar fronterizo donde ella sueña con el futuro y él se encuentra con el pasado imaginado.

Virgilio, «el extraño de mirada espectral» (183), denominación que evoca la tradición virgiliana del poeta como sombra o fantasma, inicia entonces un movimiento extraño alrededor de los amantes. A Eros el poeta le parece «un mago que, al conjuro de su danza, estrechase el círculo para aproximarles uno a otro» (183184). Con su poesía imaginada, Virgilio trata de enlazarlos mediante la magia, una cualidad que lo une con Ana. Por fin el dios recuerda quién es el extraño cuya presencia le «parece llegada de otro mundo, irreal y a destiempo»: «Desde los siglos venideros, Virgilio se ha asomado a esta historia» (184). Como en la novela de Le Guin, Virgilio ha roto las barreras del espacio, el tiempo y la ficción para encontrarse con sus personajes.

Poco después, escuchamos por fin la voz del poeta: «Sospecho que tengo fiebre» (194). No sabe si está en Roma o en Cartago, si lo persiguen las hordas de Yarbas o el misterioso desconocido. Realidad e imaginación se confunden. La fiebre, estado liminal, lo traslada al pasado imaginado y le hace reconocer al extraño que se ha colado en su mundo por una rendija del tiempo y que habla una lengua extranjera pero familiar. Es Homero que recita unos versos del libro VI de la Ilíada, que sacan a Virgilio de su impasse creativo: «He encontrado mi voz» (197).

En Cartago siglos atrás -o en la mente del poeta-, Eneas ha zarpado, Yarbas ha invadido la ciudad, Elisa ha muerto. Ana corre hacia el palacio «a ciegas, despavorida» (202). En Roma el poeta también busca su camino a casa «a ciegas» (203). En el palacio de Elisa las esclavas responden aterradas a las voces de Ana con silencio. En la casa del Esquilino también reina la calma, los esclavos duermen. A pesar de la distancia, del espacio, la ficción y el tiempo, las acciones de Ana y Virgilio parecen reflejos especulares. Virgilio ya sabe que no puede dar a su poema y a sus personajes el final deseado. Cantará sus sufrimientos, deslizará sus anhelos: «el poema épico albergará la melodía rebelde de todas las aspiraciones incumplidas» (205-206). 


\section{Conclusión: lo liminal como reflexión metapoética}

Al Virgilio de Vallejo le cuesta encontrar una voz para empezar el poema; el de Le Guin, moribundo e insatisfecho con su obra inacabada ${ }^{77}$, conversa con su personaje, que lo rebate y cuestiona. Ambos traspasan el muro de la ficción, en forma de aparición espectral, coexistiendo con sus creaciones en la misma dimensión espaciotemporal, sin que ello altere el poema. «Estoy obligado a ser fiel a la leyenda» (203): la Eneida es la que es, la que tenía que haber sido, el sufriente poema épico que nos ha acompañado durante siglos.

Dando voz a otros personajes del relato virgiliano, Vallejo y Le Guin despliegan, desde la fiel devoción al poeta, otros universos posibles dentro del multiverso de la Eneida. Un poeta sueña a sus personajes, un personaje sueña a su poeta, que a la vez la sueña... Ana y Lavinia narran la historia desde perspectivas complejas, con su capacidad de visión trascendente, pero no pueden cambiar su destino, circunscrito al poema. Sin embargo, su carácter liminal, el encontrarse a medio camino entre distintos mundos y estados, incluidas la ficción y la metaficción, permite al lector imaginar, soñar, atisbar, entrever no solo esas otras posibilidades, sino también los desgarros y desvelos de la creación literaria.

En su epílogo, Eros cuenta qué fue de Ana ${ }^{78}$ : cumplió su promesa y viajó a Italia; acogida por Eneas, desapareció un día en las aguas del Tíber, donde es venerada como una diosa acuática, Ana Perenna. Como lectores de la novela debíamos haber sospechado el final de Ana, por su fascinación con el agua, por su fluida y ambigua naturaleza ${ }^{79}$. La obra de Le Guin también termina con una metamorfosis anunciada, Lavinia transmutada en lechuza: «When the sun begins to rise and dazzle all the sky I find the dark place in the hollow oak» (286-287). El rito de paso para la vida eterna consiste en cambiar, en asumir otro ser, en volar de un sueño a otro: «One must be changed, to be immortal» (286). La doble reminiscencia ovidiana nos recuerda la dualidad de la inmortalidad de la Eneida, bella en su eternidad cual insecto atrapado en gota de ámbar, y a la vez materia maleable, flexible fibra con la que seguir tejiendo ${ }^{80}$ un perpetuum carmen.

\section{Bibliografía}

Álvarez Hernández, A.R., Leopold, S., Weiss, I.M. (eds.) (2019), Eneas: La trayectoria transatlántica de un mito fundacional, Mainz, Mainz UP.

Atwood, M. (2005), The Penelopiad, Nueva York, Cannongate.

Behr, F. (2014), «Thinking Anew about Lavinia», ICS 39, 191-212.

Sobre la cuestión, O’Hara 2010.

Ov.Fast.3.545-655; Sil.8.50-201.

Cf. «te espero sentada en el agua, mientras la arena se cuela entre mis dedos y toma la forma de mis piernas» (76).

80 «I remember every word because they are the fabric of my life, the warp I am woven on» (148); «Seguimos hablando - con metáforas textiles - de tramas, de urdimbres, de hilar relatos, de tejer historias. ¿Qué es para nosotros un texto, sino un conjunto de hebras verbales anudadas?» (Vallejo 2019, 174); «Me siento heredera de esas mujeres que siempre han tejido y destejido historias. Escribo para que no se rompa el viejo hilo de voz» (ibid. 385). 
Brown, S.A. (2012), «Science Fiction and Classical Reception in Contemporary Women's Writing», Classical Receptions Journal 4.2, 209-223.

Bugada, G. (2019), «Audire et reddere voces. La traducción como diálogo y translatio en Lavinia de U. Le Guin», Liburna 14, 67-81.

Byrne, D. (2012), «Ursula K. Le Guin's Lavinia: A Dialogue with Classical Roman Epic», English Academy Review 29.2, 6-19.

Cantó Llorca, J. (2016), «La voz de Lavinia», en De la Villa, J. y Falque, E. (eds.), Augusto en la literatura, la historia y el arte con ocasión del bimilenario de su muerte, EClás, Número extra 3, 35-54.

Cox, F. (2011), Sibylline Sisters: Virgil's Presence in Contemporary Women's Writing, Oxford, Oxford UP.

Cristóbal, V. (2015), «Lavinia, de Ursula K. Le Guin, una novela virgiliana», $C F C(L)$ 35.2, 363-376.

Farrell, J. y Putnam, M.C.J. (2010), A Companion to Virgil's Aeneid and its Tradition, Chichester, Wiley-Blackwell.

Fuhrer, T. (2015), «Teichoskopia: Female Figures Looking on Battles», en Fabre-Serris, J. y Keith, A. (eds.), Women and War in Antiquity, Baltimore, Johns Hopkins UP, 52-70.

Gaylin, A. (2004), Eavesdropping in the Novel from Austen to Proust, Cambridge, Cambridge UP.

Hardie, P. (2014), The Last Trojan Hero: A Cultural History of Virgil's Aeneid, Londres-Nueva York, I. B. Tauris.

Harrison, S.J. (1990), «Some views of the Aeneid in the Twentieth Century», en Oxford Readings in Vergil's Aeneid, Oxford, Oxford UP, 1-20.

Haydock, N.A. (2018), «Virgil Mentor: Ursula Le Guin's Lavinia», en Simms, R.C. (ed.), Brill's Companion to Prequels, Sequels, and Retellings of Classical Epic, Leiden, Brill, 375-392.

Horsfall, N. (2000), Virgil, Aeneid 7: A Commentary, Leiden-Boston-Colonia, Brill.

Horsfall, N. (2013), Virgil, Aeneid 6: A Commentary, Berlín-Boston, De Gruyter.

Hutcheon, L. (1988), A Poetics of Postmodernism: History, Theory, Fiction, Londres, Routledge.

Kay, L., Kinsley, Z., Phillips, T., Roughley, A. (eds.) (2007), Mapping Liminalities: Thresholds in Cultural and Literary Texts, Berna, Peter Lang.

Klapcsik, S. (2012), Liminality in Fantastic Fiction: A Poststructuralist Approach, Jefferson, McFarland.

Le Guin, U.K. (2009), Lavinia, Londres, Gollancz.

Librán Moreno, M. (2014), «La avifauna en la poesía latina de amor», en Moreno Soldevila, R. y Martos, J. (eds.), Amor y sexo en la literatura latina, Huelva, Universidad de Huelva, 57-93.

Lindow, S.J. (2009), «Lavinia: A Woman Reinvents Herself in Fact and/or Fiction», Journal of the Fantastic in the Arts 20.2, 221-237.

Martindale, C. (1997), The Cambridge Companion to Virgil, Cambridge, Cambridge UP.

Martino, L.M. (2017), «Irene Vallejo Moreu, El Silbido Del Arquero», REC 44, 205-210.

Miller, T.S. (2010), «Myth-Remaking in the Shadow of Vergil: The Captive(-ated) Voice of Ursula K. Le Guin's Lavinia», Mythlore 29.111/112, 29-50.

O’Hara, J. (2010), «The Unfinished Aeneid?», en Farrell, J. y Putnam, M.C.J. (eds.), 96-106.

Pease, A.S. (1967=1935), Publi Vergili Maronis Aeneidos. Liber quartus, Darmstadt, Wissenschaftliche Buchgesellshaft. 
Plate, L. (2011), Transforming Memories in Contemporary Women's Rewriting, Londres, Palgrave Macmillan.

Provini, S. (2014), «L'épopée au féminin: de l'Énéide de Virgile à Lavinia d’Ursula Le Guin», en Bost-Fievet, M. y Provini, S. (eds.), L'Antiquité dans l'imaginaire contemporain. Fantasy, science-fiction, fantastique, París, Classiques Garnier, 81-100.

Rea, J.A. (2010), «Pietas and Post-Colonialism in Ursula K. Le Guin's Lavinia», CO 87.4, 126-131.

Rivero, L., Estévez, J.A., Librán, M., Ramírez de Verger, A. (2009-2011), Publio Virgilio Marón, Eneida, Madrid, C.S.I.C.-Tirant lo Blanch.

Small, E. (2018), “"This Tiny Rivulet”: (Re)Creating the Female Voice in Classical Epic», eSharp 28, 53-66.

Teodoro Peris, J.L. (2019), «Deconstrucción y crítica del ethos épico en Lavinia (2008) de Ursula K. Le Guin», Minerva 32, 211-229.

Thomasson, B. (2014), Liminality and the Modern: Living Through the In-Between, Farnham, Ashgate.

Vallejo Moreu, I. (2015), El silbido del arquero, Zaragoza, Contraseña.

Vallejo Moreu, I. (2019), El infinito en un junco. La invención de los libros en el mundo antiguo, Madrid, Siruela.

Viljoen, H., Van der Merwe, C.N. (eds.) (2007), Beyond the Threshold: Explorations of Liminality in Literature, Nueva York, Peter Lang.

Walde, C. (2019) «Die vielen Gesichter der Lavinia-Von Vergil zu Ursula Le Guin», en Álvarez Hernández et al. (eds.), 313-344.

Ziolkowski, J.M. y Putnam, M.C.J. (2008), The Virgilian Tradition. The First Fifteen Hundred Years, New Haven-Londres, Yale UP. 